\title{
Re-thinking the Global Age as Interdependence, Opacity and Inertia
}

\author{
Oriol Poveda Guillén and Jakob Svensson
}

Uppsala University, Sweden, jakob.svensson@im.uu.se, http://www.uu.se

\begin{abstract}
In this theoretical essay we criticize theories of modernity and explore the possibility that the modern epoch is coming to a close while a new configuration is emerging: the global age. Building upon sociologist Martin Albrow's work The Global Age, we claim that Albrow's scholarship did a remarkable job at outlining the shift away from modernity, but that greater clarity is needed in laying out the main characteristics of the global age. With this essay we aim to fill that gap. Acknowledging that capitalism is the most important feature of our societies, we outline the contours of the global age through three interrelated concepts: interdependence, opacity and inertia, which in turn we exemplify with the global environmental crisis, the global economy and the Internet.
\end{abstract}

Keywords: Capitalism, Global Age, Inertia, Interdependence, Modernity, Opacity

What is modernity and what would it take for social scientists to declare it ended? These questions seem to us interrelated. The difficulty to define modernity, far from being a disadvantage, has provided it with a remarkable flexibility to incorporate new meanings and adapt to changing circumstances. It seems of little consequence that large sections of the west's industrial base have been disappearing (i.e. the postindustrial society, see Bell 1973), that the Westphalian sovereignty of the nation state has been diluted both by transnational market forces and processes of supranational integration (e.g. the European Union, see Bauman, 2000; Habermas, 2009), or that women are on their way to become half of the workforce and, increasingly, the breadwinners (see Wang, Parker and Taylor 2013). Modernity can take it all.

In this theoretical essay we criticize modernity by outlining the contours of a new epoch: the global age. Before we became acquainted with Albrow's (1996; 2014) work on the subject, we came to similar conclusions to those reached by the British sociologist. The discovery of Albrow's scholarship provided a stimulus that we were onto something. In this essay we aim to make a contribution to Albrow's global age theory by critically building on it. What distinguishes our thinking from Albrow's are mainly two points:

1) Contrary to Albrow, we consider that the entrenchment of capitalism-or, to be more precise, the explosive combination of the finiteness of the planet with the voracity of global capitalism-has played a key role in the emergence of the global age.

2) In order to better theorize the global age, we single out three interrelated concepts of particular significance, interdependence, opacity and inertia, which in turn we exemplify with the global environmental crisis, the global economy and the Internet. But before attending to the outline of these concepts, let's first take a look at Albrow's argument and the reception of his work. 


\section{Albrow and the Global Age}

Albrow was early in identifying the shortcomings of theories of modernity to account for the outlook of our time. He describes the shift that has occurred from modernity to globality and he refers to this new epoch as the global age. Understandably, Albrow devoted most of his critical thrust in outlining the epochal shift since that provided the foundation for any conceptualization on the global age. He argues that this shift has been enacted by at least five major developments: "the global environmental consequences of aggregate human activities; the loss of security where weaponry has global destructiveness; the globality of communication systems; the rise of the global economy; and the reflexivity of globalism" (Albrow 1996, 4). According to Albrow, this shift from modernity to the global age is due to processes transcending the nationstate (ibid. 91). As a result, the globe has overtaken, while not eliminating, the nationstate as the dominant frame of meaning (ibid. 106).

Albrow's The Global Age: State and Society Beyond Modernity was well received at the time of its publication, becoming one of the 1997 recipients of the prestigious European Amalfi Prize for Sociology and Social Sciences. But Albrow's work has also been widely criticized. His argument for epochal shift in particular caused resistance among his critics. Ampuja $(2011,283)$ for example criticized a lack of cogency in Albrow's argumentation, which seemed caught between declaring the newness of the global age and the fixity of the old forces of modernity. Indeed the concept of the global age requires more precision, which is what we aim to provide here. Furthermore, instead of a clear break with modernity, we conceive of our time as a transition period. We argue that it is already possible to identify the deficiencies of modernity as an overarching theoretical framework, while we start to appreciate the features of the new configuration currently emerging. But before we plunge into the characteristics of the global age, let's have a look at the mounting problems with preserving modernity as the master framework to understand our time.

\section{Modernity and its Discontents}

In a way, it is no wonder that social scientists are reluctant to forgo modernity since modernity arguably is the cradle of the social sciences (see Vásquez 2012). To break away from modernity would probably demand an intense soul-searching, starting by a review of the ontological and epistemological premises upon which the social sciences are based (ibid.). A way to rationalize away the changes that have been taking place in the last two centuries has been to discern for example "liquid" (Bauman 2000) and "late" (Giddens 1991) phases of modernity. Late modernity, in particular, is a rather puzzling concept. Scholars that subscribe to it (including ourselves in the past, see Svensson 2011) seem to possess a quite unusual skill: the ability to predict the future. What does late mean otherwise, if not that modernity is soon coming to an end, but that we are not quite there yet? Since we believe that human beings are better endowed to interpret the past than to foresee the future, we would like to suggest that the appeals to late modernity rather indicate an awareness that modernity is coming to an end but that we are not yet ready to conceptually move away from it. We are still catching up with a reality that is shifting under our feet. Our preferred understanding of late would be as recently deceased as with the phrase: the late British Prime Minister Margaret Thatcher.

Previous attempts to break away from modernity, such as postmodernity, did not fare very well and the experience might have left some theoretical scars as a warning for future challengers. Habermas (1987), for instance, fervently defended the rational 
potential of the modern age against postmodern depictions of it as a spent epoch. According to Habermas, what was presented as postmodernity was in fact a form of anti-modernity. Giddens (1991), while not disagreeing with the characterization of society provided by postmodernity (such as skepticism towards metanarratives, heightened superficiality, consumerism), claimed that rather than being superseded, modernity developed into a late modern phase. Further criticism came from Massey (1994, ch. 10) who discussed postmodernity's failure to account for feminist practices as it focused and responded to experiences of modernity among white western men (see p. 215). Leaving aside the theoretical merits or demerits of postmodernity, the name itself was rather self-defeating. Modernity seems to have been so entrenched in their way of thinking that the new could only be referred in relation to the old (see also Albrow 1996).

Critics may argue that a major obstacle to declare modernity a thing of the past is the lack of historical perspective. They will claim that modernity (in all its different forms, including multiple, see Eisenstadt 2002) is so much part of the fabric of our societies that we lack the perspective to see when it ends. This concern is legitimate, but so far it has been no impediment to chop modernity in different phases or even to predict the future. Modernity, in its various mercurial incarnations, has been stretched to embrace one thing and its opposite, both the belief in endless progress and its dismissal (Beck 1992; Scott 2004), the industrialization and deindustrialization of the West (Bell 1973) and the rise and what some argue the decline of the nation state (Habermas 2009). In the process of so much change and adaptation it is worth asking if what used to be called modernity has not eventually become something else. As Albrow (1996) already pointed out: "[m]odernity holds its adherents in a double bind: it promises new futures and at the same time denies any possibility of an alternative to itself" (1). To break away from modernity might be too harsh an expression. Modernity is rather fading away while a new configuration is taking shape. What was once solid and became liquid is now finally turning into gas. We are thus finding ourselves in a transition period: what will remain once modernity has evaporated?

The discussion about if modernity still applies is not toothless and its impact goes beyond scholarly circles. Those who insist that we have not left modernity are taking a stance that is at least as much prescriptive as it is descriptive. In doing so, they implicitly suggest that modernity provides the toolbox to tackle (or at least to understand) the current challenges faced by a quickly changing world. Some of the most pressing challenges, for instance, would be the entrenchment of the current economic system at a time in which its environmental unsustainability is a known fact, or the increasing divorce between power and politics (see Bauman and Bordoni 2014). Any sense of momentum for far-reaching change is drowned in the flow of the same narrative, an all-encompassing modernity.

As any other theoretical construction, modernity is a way of framing reality, of choosing what is brought in and what is left out, what is important and what can be ignored or sacrificed. To uphold modernity as a master narrative is often conceived in academia as a sobering exercise in lucidity — the opposite of wishful thinking - but we are concerned that such a move has also normative consequences. By offering customary approaches to new challenges, we believe that modernity and thinking within the framework of modernity are part of the problem, not the solution.

\subsection{Critics of Modernity and Globalization}

We are certainly not alone in our criticism of modernity. Giddens and Bauman-as argued above-are prominent critics of modernity but their criticism has taken place 
within the framework of modernity and, as a result, it has rather contributed to expand and flexibilize the concept in such a way that it can accommodate disparate meanings. Another well-known critic of modernity is Latour, particularly in We Have Never Been Modern (1993). Latour's thinking and ours overlap in fruitful ways (such as in the parallelisms between his understanding of networks and our concept of interdependence, see discussion below). But contrary to him we stress the salience of opacity, or in Latourian language, the fact that the increasing complexity of the networks we inhabit greatly reduces their traceability. Furthermore, while according to Latour agency is abundant and distributed among human and nonhuman actors, we conceive of human agency as significantly constrained by the opacity of the interconnections in the network (i.e. the limits of traceability) and the systemic inertia that follows thereof.

Above all we are indebted to Albrow who already in the 1990s theorized the shift from modernity to a global age. One of Albrow's main arguments was the distinction between globality and globalization. ${ }^{1}$ Whereas globalization has been theorized within the framework of modernist thought, as a process of change governed by laws and following a clear direction (1996, 93-96), Albrow's concept of globality does not refer to such a process. Unlike globalization, says Albrow, globality is not a project (ibid., 95) but rather a descriptive term to refer to a collective condition that "carries no connotation of necessary outcomes" (ibid. 5). By marking the atomic bombing of Hiroshima in 1945 and the establishment of a scientific consensus around global warming in $1995^{2}$ as the start and end points of the transition period from modernity to the global age (ibid. 2), Albrow makes clear that the collective condition of globality consists in the association of the globe with our fate as collective species (see also Albrow 2014, 128). Hence, Albrow refers to the global age as a period of time when there is an emerging awareness of human interconnectedness ${ }^{3}$, of a common fate that binds the future of humanity with the wellbeing of an endangered planet, be it by ecological degradation or nuclear warfare ${ }^{4}$.

Globalization theorists (among which Albrow sometimes is included) have been criticized for posing globalization as both the cause and the effect of the changes it purports to explain (Rosenberg 2000; Urry 2003). We should be careful though in

\footnotetext{
${ }^{1}$ In this sense we question Ampuja's (2011) criticism of Albrow for equating globalization with globality (see p. 283). Similarly Rosenberg $(2005,5)$ seems to conflate Albrow's concepts of globality and globalization.

${ }^{2}$ Through the United Nations Intergovernmental Panel on Climate Change (Albrow 1996, 1-2).

3 "The global interconnectedness of human relations brings awareness of the globe in its train." (Albrow 1996, 85).

${ }^{4}$ It seems rather telling that, while scholars in the social sciences remain reluctant to leave modernity behind, the recommendation recently presented by a group of experts at the $35^{\text {th }}$ International Geological Congress in Cape Town paves the way for the declaration of a new geological epoch-the Anthropocene. As the Greek etymology suggests, the Anthropocene would be a geological epoch marked by the human impact on the planet. In order to declare a new epoch, a globally synchronous change to the Earth system is required. The expert group considered that the radioactive fallout dispersed across the planet by nuclear bomb tests would be a promising candidate to fulfil the criteria. The new epoch, following a period of 11,500 years known as the Holocene, would have probably started around the 1950s, a time which not only registered a proliferation of nuclear bomb testing but also the beginning of the "great acceleration" (Steffen, Persson, Deutsch, et al., 2011) in environmental degradation. Compared to the shift that the geological community is currently considering, the call to social scientists to move beyond modernity seems rather modest (the Guardian, 7 January 2016. Accessed 13 September 2016. https://www.theguardian.com/environment/2016/jan/07/human-impacthas-pushed-earth-into-the-anthropocene-scientists-say)
} 
applying a general critique against globalization to Albrow's arguments. As mentioned above, Albrow makes a distinction between globalization and globality and he is also critical of globalization (not the least for its linearity, 1996, 4). Furthermore, what is meant with globalization? Rosenberg $(2000,1)$-among the most fervent critics of globalization theorists-refers to a general discourse of the increasingly unified world. Pemberton (2001) echoes a similar critique by pointing out how the normative bent of much globalization theory becomes apparent in its attachment to universalists notions and its drive to build global institutions. But global unity-including the political agenda to institutionalize it—and global awareness are two different things. By complementing Albrow's analysis with the interrelated concepts of interdependence, opacity and inertia, we distance ourselves from globalization theory at the same time that we provide one possible explanation of why global awareness has not led to global unity. Hence, we are not arguing that the emerging realization of interdependence will replace nation states any time soon (see also Rosenberg, 2000), but that it has raised our awareness beyond them.

Finally, several scholars have pointed towards new media and communication technologies as the defining globalizing factor (see Ampuja 2011, for an overview and critique of this). Taylor (2001) for example comes very close to technodeterministic when he argues that, "information and telematic technologies are recasting the very social, political, economic, and cultural fabric of life" (p. 4). As we will discuss later, we rather see the entrenchment of capitalism in its current neoliberal shape as the dominant feature of our societies (see also Fukuyama 1992; Thussu, 2006; Fuchs 2014), and thus also as a key player in the emergence of the global age. $^{5}$

\section{Interdependence, Opacity and Inertia in The Global Age}

Our contribution to global age theory consists in spelling out what we claim are three interrelated concepts to understand this new epoch: interdependence, opacity and inertia. We will come back to these concepts below. As much as we take Albrow's work as our point of departure, we are reluctant to join him in affirming that we live already in the global age. According to Albrow $(1996,2)$ Hiroshima and the establishment of global warming as a scientific fact by the IPCC (United Nations Intergovernmental Panel on Climate Change) marked the start and end points of the transition period from the modern to the global age. We speak rather of the global age as a new epochal configuration that is rapidly emerging and whose features are already distinguishable from the debris of modernity. We are thus not implying a clear-cut shift into a new epoch, rather that we are living through a transition period (see also Ampuja 2011). We are hesitant to join Albrow in his search for central events that act as catalysts or turning points, since in our account other events such as the fall of the Soviet Union would have been equally momentous and, in the last analysis, epochs change because of an aggregate of factors. Furthermore, given that modernity has at least two levels, as an account of an empirical reality and as a theoretical construct accepted by a majority of scholars, the transition period will not end until both levels have been transformed. We are fairly confident that the empirical side of the argument is becoming increasingly apparent. As for the theoretical side, we are in no illusion that this essay will sway the scholarly community, but we hope that at least it

\footnotetext{
${ }^{5}$ Here we differ from Albrow in that he advocates a multidimensional analysis and is thus not giving capitalism the same salience as we do (see also Ampuja 2011, 283).
} 
makes readers ask themselves what it would take for them to drop modernity as their master framework.

We do not wish to suggest that the global age applies in the same way and to the same extent to people in all cultural contexts. The habit of making very wide claims, often verging on the universal, is deeply ingrained in western scholarship and theoretical discourses around modernity have not been an exception. It is of little consequence that those claims are often only relevant to western contexts (see for instance Joseph, Reddy and Searle-Chatterjee 1990). In the following sections, we will also write from a western perspective but not because we believe, implicitly or explicitly, that western patterns are always universally explicatory. To what extent our claims apply or not to other contexts is a task that, if they so wish, other scholars writing from different latitudes are in a much better position to assess. Furthermore, the expression global perspective is an oxymoron. Perspectives are always partial and located. We believe, therefore, that acknowledging our partiality and locatedness is not an impediment when writing about the global but rather a necessary exercise in epistemological humility.

\subsection{Interdependence and Opacity}

Let's begin with interdependence and opacity. In the global age, there is an increasing awareness that everything is connected with everything else. Albrow $(1996,85)$ mentions increasing interconnectedness in passing, but while he argues that interconnectedness makes it possible to conceptualize global risks, we would contend that the links that constitute those connections are extremely difficult to trace beyond a few steps. Given the complexity and interconnection of the systems we inhabit, individual actions create something resembling a myriad of ripple effects in an echo chamber. As individuals we make incremental interventions but as societies we witness the full-blown consequences of our aggregated doings. Ripple effects may become large waves, even tsunamis, or-in real world terms-the likes of environmental catastrophes or global economic cycles of boom and bust (see also accounts of the end of certainty and chaos theory in Urry 2003, 22-23). The links, though, between those interventions and the larger consequences they carry are opaquely perceived and not fully understood. Although there is a sense that individual acts feed into much larger processes, the myriad of intervening factors make it impossible to accurately trace the consequences.

The idea of opaque interdependence resonates with complexity and complexity theory (see Tomlinson 1999; Taylor 2001 and Urry 2003). Urry (2003) for example refers in passing both to the terms interdependence (when he discusses Giddens globalization theory, see p. 39) and opaqueness (when discussing the workings of pervasive computing, see p. 73). However, complexity theorists seek to explain or disentangle complexity, make complexity less complex. Taylor (2001) for example states that it is "necessary to understand complexity as comprehensively as possible" (p. 14) and Urry (2003) that complexity theory has as its aim to investigate "regularities of behavior" (p.13) and the establishment of patterns (p. 121). We would rather argue that the opaqueness that builds up with complexity makes the theoretical endeavors to disentangle the latter increasingly precarious. For that reason, we do not seek to shed some light in the opaque workings of interdependence as much as to establish it as a condition we are starting to reckon with. We are moving from a view of the world as something intelligible through reason and intellectual effort to a world whose complexity we struggle to grasp and yet we still have the capacity to destroy. In other words, we rather seek to connect opaque interdependence to Albrow's dis- 
cussion concerning global awareness. In this sense our account is also different from Tomlinson (1999), who equates globalization with complex connectivity (p.2). Contrary to us, Tomlinson seeks to discuss global unity through the dissolving of locality (i.e. deterritorialization). Our elaboration of the global age is not one of global unity through interconnections, but rather-to put it in the starkest terms-of disunity and lack of political action despite global awareness.

The emotional responses to opaque interdependence vary, but an increasing awareness about the unsustainability of the western lifestyle is leading to a heightened sense of anxiety. The pleasure of consumption is far from being over, but it has forever lost its innocence. The thought of sweatshops, $\mathrm{CO}^{2}$ emissions and deforestation, just to mention a few, has spoiled the pleasure of consuming cheap clothing, charter flights and fast food. The repercussions for consuming such goods and services are not clear-cut. It could be argued, for instance, that the exploitative labor conditions in a sweatshop-and the entrenchment of poverty that results thereofcan have larger social and political consequences ranging from environmental degradation to terrorism. In this sense, everything is increasingly perceived as being connected with everything else, a cheap sweater in a London store with jihadism in the tribal areas of Pakistan, while the links themselves of those connections are only partially and opaquely grasped. The idea that everything is connected with everything else is, in fact, a form of interdependence. These two apparently contradictory concepts-interdependence and opacity in the interconnections, or rather, the awareness of interdependence without the full grasping of its inner workings-are two of the main features of the global age ${ }^{6}$.

\subsection{Inertia}

The third characteristic of the global age, inertia, tells us that the ability to engineer change in a system, is conversely proportional to the complexity of the system in question. Inertia, however, should not be confused with predictability. By failing to adapt their behavior in response to warning signals from their environment, inertial systems tend towards chaos and entropy. Inertia reflects a shift in our conception of the forces that shape-enabling or preventing-social change. While Albrow (1996, 83-85) argues that global interconnectedness makes globality an ever present aspect of human calculation and leaves open the question of human agency, we would contend that opaque interconnections contribute to stifle agency (in contrast also to more celebratory accounts of cosmopolitanism as we will attend to later). But in order to understand what has changed we need to take a brief detour through the structuring principles of society that have dominated previous epochs. In what social scientists came to call traditional or pre-modern societies (see Giddens 1991), the hierarchical structure of society was conceived as preordained by God who created it in harmony with the rest of the universe (Taylor 2007). In its conception of the structure of society, the modern age made the opposite move: control was wrested from the hands of an omnipotent deity and put men (intentional gendered form) in charge (Taylor 2007). That was the principle animating the age of reform and revolution. The idea that men created their own social reality in interaction with each other was translated in the concept of social constructionism (as in Turner's [2008] definition of "a critical theory that shows how social structures are merely "man-made" [sic] rather

\footnotetext{
${ }^{6}$ In his recently published work, Albrow $(2014,74)$ also seemed to have some intimations about the importance of opacity when he wrote about "a world that we have only partly made, under conditions not of our choosing, where we don't know and will never know everything relevant to our decisions" (our emphasis).
} 
than immutable conditions" [493]). Furthermore, social constructionism provided a basis for reflexivity, the idea that the self and the world around it was not a given, but a project to model and shape according to the individual's desires and circumstances (Giddens 1991).

If we agree that capitalism is the single, most important feature of our societies (see Fukuyama 1992; Thussu 2006; Fuchs 2014) we may observe how a third option is currently taking shape. The modern epoch marked the transition from a world ruled by God to a world ruled by men. In the global age, the anthropocentrism of the former period is called into question through the pervasiveness and inertia of a phenomenon such as capitalism, which trumps (although it does not completely cancel) human agency. In our time, capitalism has gained such momentum, is hegemonic in such an unprecedented way, that it is continuing to develop through a logic of its own. Although human beings were crucial in setting capitalism in motion, we would claim that the present form in which it appears to us was neither engineered nor planned by human ingenuity. Even though it could be debated when capitalism began (see for instance Perelman 2000; Wallerstein 1995), we conceive of its protracted genesis as the result of countless intervening factors, both human and nonhuman, accumulated through the span of thousands of years and which, like layers of sand in a sedimentary rock, have coalesced creating the phenomenon in question. At the dawn of the global age, we find ourselves inhabiting a system that we do not fully understand and much less control. Capitalism seems to have taken on a life of its own. Those who profit most from it have been successful at exploiting it, but rarely at controlling it. With contemporary capitalism we can say that modernity's juggernaut (Giddens, 1990 ) is finally running out of control. We discover that no one is sitting at the steering wheel and that the havoc it is unleashing poses a plausible threat to the future of humanity.

It is important to see capitalism here as a system that has grown organically through history, not through a readymade design. The attempt at introducing design has rather come in at a later stage. Arguably, one of the reasons why the deterministic strands of Marxism failed was that they presented as an inevitable historical development what was rather an attempt to engineer a new order. Soviet-style 'real socialism,' far from deriving from the laws of history, was called to abolish a status quo that was formed during thousands of years by the accumulation of human and nonhuman circumstances (availability of natural resources, climate, topographical conditions for trade, et cetera). We do not mean to say that social engineering of the scale attempted by 'real socialism- is impossible or even desirable, only that the challenges facing such a project are colossal. Likewise, we are not suggesting that the social order is static. The point is that social orders do change, but at least in our time those changes follow trends that are much more embedded in the inertia of capitalism than in human agency and foresight.

We would argue that a way to conceptualize the relationship between the inertia, blindly driving forward capitalism, and human agency is to speak of them in terms of vector and corrector ${ }^{7}$. In our own definition, a vector is the dominant force that marks the direction that society follows. Correctors, on the other hand, can be understood to accelerate or slow down the course that society is following. Correctors can also make marginal changes in the direction and they can even force society temporarily into a new course, but sooner or later the force of the vector reasserts itself and

\footnotetext{
${ }^{7}$ Please note that this is a simplified model of limited use aimed solely at illustrating the relationship between capitalism's inertia and human agency.
} 
brings society back to its former track. Otherwise, a corrector would have become the new vector, taking over the leading role in the process. A good example of this is how in the aftermath of the 2008 financial crisis the then French President Nicolas Sarkozy echoed the opinion of his peers in the political elite when he declared the need to "refonder le capitalisme". A few years later, Wall Street was back to business as usual. In spite of that, it is nowhere written that capitalism's inertia must remain the vector and human agency the corrector. Those roles could change, but what characterizes the present moment is a growing awareness of how capitalism has run out of control and is driven by its own inner logic, at the same time that counter-hegemonic movements are not potent enough to reform or overcome capitalism (see for example Habermas 2009). There is no question that there are people who profit enormously from this state of affairs (the famous 1\%) but even their influence has a limit. They belong to a particular type of correctors, the accelerators (those who make society advance much faster in the vector's direction, towards increasing inequality and a further erosion of democracy), but they neither have the power nor the internal cohesion to establish a new vector single-handedly.

The inertia that currently drives capitalism depends for its existence on the phenomenon discussed previously of opacity. The paralyzing effect that opacity has on human agency, the fact that we have been made dependent of systems that we do not understand, is what enables the wheels of capitalism to continue turning aimlessly. On the other hand, due to our interdependence we are so enmeshed in the global capitalist system that resistance demands nothing short of unlearning how the world works and reinventing ourselves in radical ways, which would probably put us outside the pale of society.

Complexity theorists have also theorized in similar ways to how we described inertia above, trying to articulate that there is some order in complex systems that at face value seem disorganized. Urry (2003) for example writes about the systemic and the dynamic character of capitalism (3), about a complex non-linear world that is disorderly but not simply anarchic (preface p. x). Similarly Taylor $(2001,4)$ argues that significant change takes place between too much and too little order and hence also underlines that complex systems do not operate in complete random ways. Inertia, as we have described above, nicely combines-within the concept itself-a sense of trajectory with a lack of predictability. Indeed, one of the characteristics of inertia is that at a time of crisis it is unresponsive to warning signals from the environment, thus descending into chaos and entropy. Although we acknowledge our affinity with complexity theorists, we prefer our choice of concepts (interdependence, opaqueness and inertia) since they provide a clearer and more stringent conceptual apparatus. In conclusion, we may say that inertia follows logically from the combination of interdependence and opacity. Once we are made dependent of systems we do not fully understand or control, the result is that our agency is compromised and those systems continue to develop according to a logic of their own and with unintended consequences.

\subsection{The Interrelatedness of Interdependence, Opacity and Inertia}

In this section, we would like to stress the point that the three concepts we have chosen to describe the global age, are not free standing terms but exist in relation to each other.

\footnotetext{
${ }^{8}$ See Le Figaro, 26 September 2008. (Accessed 5 June 2015. http://www.lefigaro.fr/economie/2008/09/26/04001-20080926ARTFIG00034-nicolas-sarkozy-veutrefonder-le-capitalisme-.php).
} 
Interdependence and interconnectedness are not synonyms. Whereas the former introduces notions of distributed agency and mutual reliance, interconnectedness simply states that links exists between the nodes without making any qualitative assessment regarding the nature of those links. We are aware that arguing for interdependence is a stronger claim than doing so for interconnectedness. Yet as the examples in the next section illustrate, in an interdependent situation no one actor can decide outcomes single-handedly. Rather, actors are entangled with a multitude of other actors each having a particular stake and varying levels of influence in the outcomes of the process. Furthermore, the pervasiveness of capitalism has also created a thick web of interdependencies in which social, political and environmental factors are enmeshed with economic relations (see section 2.1 above). In this sense, one possible reading of interdependence is as a consequence of capitalism's growth imperative and its attending drive to expand into new markets and to integrate them according to the interdependent logics of trade, consumer demand creation and division of labor, to mention just a few. The entrenchment of capitalism, in turn, has disturbed a far more comprehensive system (i.e. the biosphere) from which all life depends, creating the sense of impending environmental crisis. ${ }^{9}$

The emergence of interdependence has been clearly a multi-factor process in which the explosive interaction between capitalism and a finite planet has played a key role. From the perspective of the individual, though, there is an awareness of interdependence generated to a large extent by the consumption of goods and services produced in faraway shores (goods and services that most of us would not be able to produce ourselves) and the "mainstreamization" of environmental concerns. However, when it comes to tracing in detail the intersecting links of dependency, the analysis breaks down pretty quickly due to the enormous effort that the task requires as well as the mindboggling complexity of the systems we inhabit. Opacity then emerges as a result of the complexity of our interdependencies, out of the fact that we inhabit and are made dependent of systems that we (and no one else, for that matter) do not fully grasp. It should be made clear that opacity does not necessary follow from interdependence. It is rather the build-up of complexity, through the myriad of intervening and not always predictable factors, which gives rise to opacity. This leads us then to the third and final concept, inertia.

As we mentioned before in section 3.2, inertia should not be confused with the predictability of a steady course (or autopoesis, see Urry 2003, 101). Inertia is much closer to notions of thoughtless movement or of a rock blindly tumbling down a slope. Inertia, therefore, implies a comment on human agency, which becomes significantly impaired under conditions of opaque interdependence. The opacity we described has a paralyzing effect. To change a system one does not fully understand, but is made to depend from, is a daunting task not only because one does not really know from where to begin, but also because by becoming clients ${ }^{10}$ of the system there is a legitimate fear that the alternative will leave us worse off. Folk wisdom says "if it works, don't fix it" and as long as capitalism is made to work for enough people, the deferral continues. Interdependence, then, tends to the loyalization of the system's clients

\footnotetext{
${ }^{9}$ Reckless environmental degradation caused by human activity is obviously not exclusive of capitalism, as the catastrophic draining of the Aral Sea initiated in the 1960s by the Soviet Union illustrates or as Diamond (2005) has documented in a variety of historical and cultural contexts ranging from Easter Island to the Mayas or the Icelandic Vikings. Capitalism, though, is not just the last of a long list of extractivist systems (Klein, 2014), but notably the only one that has reached global hegemony. That level of pervasiveness makes capitalism qualitatively different from its predecessors.

${ }^{10}$ Client understood as "anyone under the patronage of another; a dependent" (Dictionary.com. Accessed 21 September 2016. http://www.dictionary.com/browse/client).
} 
who in its absence would feel rather helpless. On the other hand, the opacity emerging from the complexity of the web of interdependencies hinders the gathering of sufficient knowledge regarding the workings of the system and thus stifles our ability to make informed and strategic interventions conducive to systemic change. The net result, in terms of agency, is what we call the crisis of reflexivity (see section 5) and the continual engagement in capitalistic practices that we know are harmful to ourselves and others. Inertia in this case is then the situation that arises when capitalism is left to itself and takes a life of its own. All the above does not mean that such kind of self-destructive inertia is mandated by fate. Clearly there are ways to handle interdependence, reduce opacity and curve inertia, but that is material for a different paper.

As we have hopefully managed to argue, interdependence, opacity and inertia are not isolated concepts that we have randomly chosen to characterize the emerging global age ${ }^{11}$. Our three core concepts unfold from each other and, with each unfoldment, they interact in new ways providing a richer account of the emerging global age. In that sense, as much as we acknowledge our affinity with previous theoretical efforts by globalization and complexity theorists, we believe that we make a contribution by narrowing down our analysis to what we regard are the three core concepts and weaving them together into a coherent whole.

\section{Three Examples}

Let us now turn to three phenomena that, from our western vantage point, seem suitable examples to illustrate the main features of the global age: the environmental crisis, the global economy and the Internet. These phenomena echo three of the five major developments that Albrow $(1996,4)$ already identified as harbingers of the global age. Furthermore, they all contribute to the fading of the nation-state as the main horizon for individual awareness that Albrow (1996, 99, 128-133) repeatedly returns to as a major sign of the break away from modernity. An essential feature that these phenomena have in common is that each of them, in its own way, is subordinated to capitalism. This is most obvious in the case of the global economy, but also recognizable in the other two. If we take the example of the global environmental crisis we can observe how the inertia of capitalism has managed so far to trump attempts to significantly reduce its ecological impact. Concerning the Internet, the initial hopes for a free and democratic medium of communication for the masses, have lately given way to the dominance of a few for-profit conglomerates such as Google, Facebook and the like (see van Dijck 2013; Fuchs 2014). In other words the Internet has become subservient to economic interest and, as a result, it has fallen under the sway of the inertial forces that drive capitalism. The rise and fall of Pirate parties across Europe (Iceland being the exception) and the political agenda they promoted (see Burkart 2014) is a case in point of how short-lived the idealism surrounding the Internet has been.

\subsection{The Global Environmental Crisis}

The global environmental crisis is probably the phenomenon that most clearly captures the interdependencies of the global age. The crisis is due to the human impact on the biosphere, which is also the cause for climate change or, in the words of the IPCC, "human influence on the climate system is clear" (IPCC Fifth Assessment Re-

\footnotetext{
${ }^{11}$ To further understand the ways in which interdependence, opacity and inertia are interrelated, see the concept of "emergent causality" as discussed by Bennett (2010, 32-33).
} 
port from 2014). The Earth, as a self-contained ecosystem, works as a resonance chamber. If oil is spilled at sea, currents will carry it to faraway shores. If there is a nuclear meltdown, the radioactive cloud might travel hundreds of miles before it wears off. Nature does not know of borders or international treaties. The environmental movement has highlighted this aspect of interdependence on a planetary scale by rallying around the climate change issue. ${ }^{12}$ The failure of one large economy to cut down $\mathrm{CO}^{2}$ emissions may have dire consequences for the rest of the world. By reducing the planet's ability to absorb $\mathrm{CO}^{2}$, the destruction of large areas of rainforest is generally considered to accelerate global warming. We are talking here about massive systems that take a long time to heat up and a long time to cool down ${ }^{13}$. Both industrialized and agrarian nations have a stake in this question, as well as means to influence the final outcome. As a result, international cooperation among countries from both hemispheres has become part of the global political agenda to forestall climate change (i.e. the UN's climate summits). At the same time, the Earth's climate is an extremely complex system that challenges current scientific models, which are able to predict long-term trends but are much less reliable when it comes to accounting for shorter time spans. Opaqueness comes as a result of our limited knowledge and the constant influx of new data and variables that would need to be integrated in a comprehensible model. That the global mean surface temperature has increased in $0.85^{\circ} \mathrm{C}$ over the period $1880-2012$ is an empirical fact (IPCC, 2014, 62, 189). However, at what moment we will reach the so-called tipping point-if we have not reached it already-is still a matter of debate. Hence, we become wiser in hindsight, being much more successful in assessing the past than in describing the present or predicting the future. Finally, as a phenomenon caused by extractivism (Klein 2014), climate change is also under the sway of the inertial forces driving capitalism.

\subsection{The Global Economy}

The global economy, too, presents a similar admixture of interdependence, opacity and inertia. In general terms, we would describe economic globalization in a capitalist system as a process in which private companies take advantage of low labor costs in so-called developing countries, as well as liberalization and deregulation of markets worldwide, in order to maximize profits. However, the expansion of economic activity across continents on an industrial scale has created a new set of interdependencies. The cliental relationship between the US and China is a case in point: while the US is the second largest importer of Chinese goods and services, the Chinese government is the largest foreign holder of US debt. ${ }^{14}$ The interdependence and global embrace of the economy is even clearer in the case of the highly volatile and deregulated financial markets (see for instance the cases of high frequency trading and derivatives markets). The growing complexity of the global economy and the financial markets has brought about the paradoxical result that, although a product of human ingenuity, no individual or institution possesses a thorough understanding of how those sys-

\footnotetext{
12 See for instance the massive climate change march that took place on 21 September 2014, in New York (New York Times, 22 September 2014. Accessed 21 May 2015.

http://www.nytimes.com/2014/09/22/nyregion/new-york-city-climate-change-march.html? r=0)

${ }^{13}$ See for instance Meehl, Washington, Santer et al. (2006) in relation to the concept of climate change commitment.

${ }^{14}$ See for example the figures provided by the US Treasury (Accessed 21 May 2015.

http://www.treasury.gov/ticdata/Publish/mfh.txt.
} 
tems work. ${ }^{15}$ Part of the problem, of course, is that the global economy, as the biosphere, is in constant change and any satisfactory understanding of it would need to keep pace with a vertiginous flow of fresh data. Opacity in the interconnections of the world's economy has grown as the unintended outcome of expansion and sophistication. And as complexity increases, human oversight has been under pressure to keep pace with it.

\subsection{The Internet}

Finally, the Internet is a human invention that makes individuals and institutions increasingly dependent on each other, creating a dense web of intersecting information networks (van Dijk 2012). For the common user, the overall functioning of the Internet is an arcane matter, but not even the expert can keep pace with the colossal amount of information that is being erased, modified or uploaded constantly. In the global age, the experts of Beck's (1992) risk society are increasingly under pressure, if not already overwhelmed, by the complexity of the systems under their watch. As with Socrates' adage, experts in the global age are those who know that they know (almost) nothing. The consequence of this state of affairs is that no satisfactory understanding about the scope of the Internet exists: the core might be continuously mapped and remapped by high-tech giants such as Google and the like, ${ }^{16}$ but around an island of relative certainty there is a vast and polymorphous expanse of freefloating data. The part of the Internet that is not indexed by search engines, the socalled deep web, is said to be up to 500 times larger than the so-called surface web (Bergman 2001). Indeed, as the complexity and interdependence of the systems we inhabit increase, so does the amount of data they generate (see also Urry 2003, 64). But the capacity to produce and distribute data has not been matched by the ability to make sense of it, that is, to integrate data into a larger framework of meaning. Not even the promise of big data has been able to deliver that. One reason is that big data is a relative term. It is big compared to what human beings alone can process, but it is small compared to the amount of data potentially available. Furthermore, while big data is good in presenting the bigger picture, it cannot tell us why something is happening or why people behave in a particular way. The main reason for this widening gap between the data produced and making sense of this data is that the first operation is increasingly being automatized (as the concept and practice of robot journalism highlights, see van Dalen 2012), while the second requires the intervention of human judgment. All the data that cannot be assimilated becomes noise and contributes to the opacity of the systems we inhabit, which in turn could make us passive, stifle our agency. Information overload, or infobesity/ infoxication, implies a state where one is no longer able to manage and handle the information (Deuze

\footnotetext{
${ }^{15}$ In the words of Cathy O'Neil, a mathematician (PhD at Harvard, post-doc at MIT) and former quantitative analyst at a hedge fund: "Nobody knows how the system works. Even the people in finance don't understand the system. They understand their little corner of the system. If it's securitized products, they understand how that works. If it's, you know, arbing [arbitraging] the equities market, they understand how that works. But very few people would come forward and say: "I'm an expert on the financial system. I know how everything works." Excerpt from O'Neil's interview for PBS Frontline's 4 part series documentary Money, Power and Wall Street (Accessed 21 May 2015. http://www.pbs.org/wgbh/pages/frontline/oral-history/financial-crisis/cathy-oneil)

${ }^{16}$ See the Internet Mapping Project (Accessed 2 June 2015. http://en.wikipedia.org/wiki/internet_Mapping_Project)
} 
2012), a state when the amount of input to a system exceeds its processing capacity (Speier, Valacich and Vessey 1999). This is a far cry from the initial and perhaps utopic visions of the Internet as something expanding the human mind and furthering collective intelligence (see Lévy 1997). In other words we are referring to the paradoxical relationship between knowledge and comprehension. Increases in knowledge translate themselves into increases of comprehension as long as the new information pouring in can be filtered and integrated into larger frameworks of meaning. Indeed Taylor (2001) opens his book, The Moment of Complexity, describing such moment as the time "when things are changing faster than our ability to comprehend them" ( $p$. 3 ). When this relationship is altered and the increases in knowledge can no longer be assimilated, the process starts to produce noise which, at high concentration levels as the one we are currently experiencing, has corrosive effects on comprehension. We have fairly limited information processing capacity and hence when information overload occurs, that is likely to impact comprehension as well as our ability to make decisions out of systems overloaded with information (Speier et al. 1999). If this trend towards information overload does not revert we will find ourselves in the situation that the more we know the less we comprehend.

It thus seems that the Internet (as well as the global economy) have mimicked the biosphere in developing a life of their own beyond human control. Individuals and societies increasingly realize that they have been made dependent on a series of global systems that they do not fully grasp and whose outcomes they cannot satisfactorily predict. In such scenario, the need to cooperate internationally-not out of a selfless inclination, but necessity-becomes one of the distinctive features of the global age. No single state or society, regardless its economic and military might, can handle alone the global threats to which it is exposed. It is a truism that global problems demand global solutions. The overwhelming and constantly changing amount of data necessary to calibrate the response to real or imagined global crises cannot be assimilated by any single government body. Institutions find themselves under an increasing pressure to pool their resources together and constitute larger networks, the European Union being a case in point. International cooperation not only is an acknowledgement of interdependence, it is also a strategy to reduce opacity in the different systems under scrutiny. This combination of interdependence and opacity underlines yet another consequence, a heightened sense of precariousness. The higher the interdependence, the greater is the vulnerability of the system as a whole (as illustrated by the 2007-08 financial crisis). Furthermore, the more opaque the workings of the system are, the more difficult to manage and predict its outcomes. The sense of precariousness, in spite of all technological progress and expertise, has invested the global age with a sense of apprehension for the future that, so far, has failed to translate into a decisive agenda for change.

\section{Reflexivity in Crisis}

Largely due to the influence of the work of Giddens (1991), reflexivity has been singled out as one of the defining characteristics of late modernity. Reflexivity has been understood as the process by which people evaluate different alternatives and make rational choices about how to live their lives. Giddens (1991) referred to a reflexively organized endeavor, and to be successful in this, the individual needs to possess an ability to construct, deconstruct and reconstruct their self-identity and biography. Hence, rationality for Giddens refers to the urge among late modern individuals to create a coherent biography. As a result, we experience a need to think reflexively about who we want to be and align our actions accordingly (see Svensson 2008). As 
an increasing number of people were released from their attachments to tradition, more and more areas of life opened up to a variety of choices, which provided the building blocks for the construction of personal biographies (i.e. the self as a project, see Giddens 1991). This picture was probably fairly accurate for the western educated middle classes until not so long ago and particularly during the decades of economic boom of the 1960s and 1970s when industrial output was high, household incomes increased sharply and conspicuous consumption became a mass phenomenon (see for instance, Mason 1998). Although not to be confused with consumer's choice, the idea of reflexivity suggests a universe of endless possibility: identities became fluid and almost every aspect of human life could potentially be redefined, negotiated and transformed in the search of increased well-being, satisfaction and meaning (Elliot 2001).

In the global age, this type of reflexivity has entered in crisis. The ethos of endless possibility and fluidity enabled by the western lifestyle has crashed against the stubborn ecological limits of our planet. While reflexivity in so-called late modernity was presented as freeing people in the west from 'the chains of tradition,' thus allowing us to explore our true selves, in the global age reflexivity about ourselves and our lifestyles will inevitably remind us of the unsustainability of western, identity-centered lifestyles. While so-called late modern reflexivity was about controlling the image of ourselves, in the global age reflexivity implies a realization that we humans are not in control (see also Albrow 1996, 136). This crisis of reflexivity seems particularly acute among sections of the educated middle classes, that is, those who received higher education and who have been made aware of how their lifestyle based on the consumption of goods and services from the global market is causing rapid environmental degradation and great social and economic disparities the world over. In this new scenario, reflexivity has ceased to be a means to personal fulfillment and has become a liability. To be reflexive in the global age is to remind oneself that the western lifestyle (around which the late modern individual has spun their web of meaning) is unsustainable and, to a significant extent, maintained at the expense of others, often underpaid farm laborers and irregular workers located both nearby and in faraway lands without union rights or legal protection. Given the gloomy future scenarios spelled by the continuation of unsustainable lifestyles, it seems that the preservation of the current organization of society depends on consumers making irrational choices on a daily basis, or making no conscious choices at all, sticking to old habits that let capitalism continue its course (i.e. inertia). In other words, the maintenance of a western lifestyle increasingly requires that reflexivity be stifled or at least selectively deployed. Reflexivity is under pressure to shift into a form of selective amnesia aimed at leaving out of the mental map the ways in which personal choices have a negative impact both at the local and the global level. This is different from Beck's (1992) risk society. While risk society led to a loss of faith in experts in the global age, we have lost faith in ourselves and our possibility to change this world, while at the same time becoming aware of our capacity to destroy it. This is very different from the mobile, curious and open cosmopolitan that Urry $(2003,133)$ portrays. We argue that global interdependence has not led to panhumanity (ibid.136), the positive feeling of simultaneously living in the local and the global (ibid.137). In contrast, we argue that global interdependence has led to a stifling of human agency. In other words, in the global age the cosmopolitan has become disillusioned.

The account given above could give rise to a bleak interpretation in which individuals with western lifestyles are helplessly entangled in a self-destructive system, and isolated initiatives to make a difference are negligible compared to the impact of the 
conforming majority. This reading would be accurate at the level of the individual, that is, the level usually privileged by the advocates of modernity (in its different forms). In contrast, we would argue that in the global age there is the potential for a shift of focus towards the collective as the major force for social change. Instead of the inwardlooking project of the self, the global age provides a fruitful ground for the emergence of an outward-looking gaze in which the needs and perspectives of other living beings (including non-humans and future generations) are taken into account in the construction of one's identity and life's project. ${ }^{17}$ An increasing awareness of interdependence has the potential to bolster a reappraisal of the collective condition intrinsic to the global age and to encourage the formation of new movements and forms of political action aimed at reducing opacity and regaining democratic oversight.

\section{Summary and Conclusion}

In this essay we have contributed to Albrow's global age theory by critically building upon it. We have singled out capitalism-or the explosive combination of the finiteness of the planet with the voracity of global capitalism-as a major force in the emergence of the global age. We have also identified three interrelated terms interdependence, opacity and inertia-as core concepts for understanding the global age and discussed how they unfold and subsequently interact with each other. We used the global environmental crisis, the global economy and the Internet as examples to illustrate our points.

By building upon Albrow we have argued against modernity as the master narrative of our time. Contrary to Albrow, though, we have not described a clear-cut break with modernity. Rather we conceive of our time as a transition period in which we can already identify the deficiencies of modernity as a theoretical framework to account for the present, while starting to appreciate the features of the emerging global age. In a similar vein, we argue that modernity has lost its sharpness as it can include different and contradictory meanings. If the definition of modernity is sharpened, it still can be useful on the theoretical level to describe the epoch we are moving away from. On the empirical level, however, we argue that modernity as a theoretical framework increasingly fails to account for the emerging trends that we attempt to capture with our three interrelated concepts. It is in that regard that modernity should be discarded, since it falls short in accounting for the world of opaque interdependence and stifled agency in which we live.

An important feature of Albrow's global age is his distinction between globality and globalization. Globality is not a project but a collective condition consisting in an awareness of human interconnectedness, of a common fate that binds us with the wellbeing of the planet under threat from nuclear warfare and ecological degradation. This distinction is an important one as it underlines that nation states not necessarily will be replaced any time soon (as some globalization theorists have argued and been criticized for). Rather, in the global age it is our awareness that has reached beyond the boundaries of the nation state. In other words, we distance ourselves from globalization theorists who rather focus their efforts on the study of processes geared towards global unity. Our elaboration of the global age is not one of global unity through interconnections, but rather of disunity and lack of decisive political action despite of global awareness.

\footnotetext{
${ }^{17}$ In relation to this, see also Albrow's (1996) concept of performative citizenship, from which we depart in significant ways (see discussion about agency in section 4.2).
} 
The thrust of the essay has been to relate Albrow's analysis of global awareness with the three interrelated concepts of interdependence, opacity and inertia. In the emerging global age, there is an increasing awareness that everything is connected with everything else. However, the connections are only opaquely perceived and not fully understood. Furthermore, we contend that opaque interconnections contribute to stifle human agency. It seems capitalism has entered an inertial phase largely driven by the opacity resulting from its growing complexity and interconnectedness. Another way to put that is to say that the combination of interdependence and opacity (the fact that we have been made dependent of systems that we do not fully understand) has had a paralyzing effect on human agency. Once we are made dependent of systems we do not fully understand (and even less control), the result is that our agency is compromised and those systems continue to develop according to logic of their own, and with unintended consequences. Interdependence, opacity and inertia are thus not isolated concepts. They unfold from each other and, with each unfoldment, they interact in new ways providing a richer account of the emerging global age.

In this elaboration we have not sought to shed light into the opaque workings of interdependence as much as to establish it as a condition we are starting to reckon with. We are moving from a view of the world as something intelligible through reason and intellectual effort to a world whose complexity we struggle to grasp and yet we still have the capacity to destroy.

\section{A Final Note on Rivera}

We are aware that any argument to introduce a new theoretical framework must measure itself against the merits of the incumbent in explaining the same phenomena. In the case of modernity, this is not a question that can be answered in a few lines. Instead, we suggest taking Diego Rivera's mural Man, Controller of the Universe (see figure 1) as an iconic representation of modernity in order to see how far we have removed ourselves from it at the dawn of the global age.

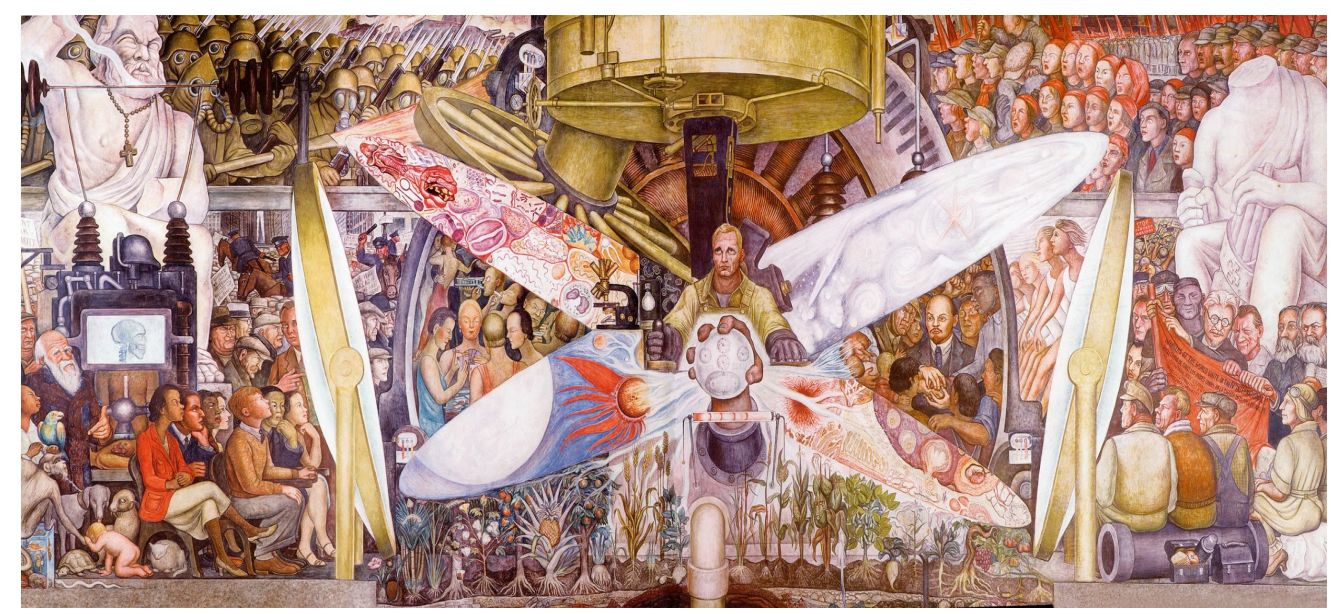

Figure 1. Diego Rivera's Man, Controller of the Universe (1934) as displayed at the Palacio de Bellas Artes, Mexico City. The mural is a reconstruction of the original work, Man at the Crossroads, commissioned and subsequently destroyed by Nelson Rockefeller due to its positive depiction of Soviet motives.

If we look at the mural starting from the sides and moving towards the center, the first thing that draws the attention of the observer is the depiction of humanity divided in two ideological camps, capitalism and socialism. In its multifarious forms, the struggle 
between capital and labor has been one of the defining characteristics of modernity and its importance has remained unabated until today. This struggle, however, is a struggle between people engaged in competing models of human organization. In the global age, we witness the rise of a new form of struggle, not between different groups of people, but rather between humanity as a whole and its own shadow. In this context, the adversary is not someone waving a different flag from ours, but the destructive powers of humankind unleashed by unprecedented technological progress. In the global age the debate is not only about a model of human organization. Rightly or wrongly, what seems to be at stake is the fate of the planet as a whole. If we direct our attention now to the center of Rivera's mural, we see the figure that gives the work its title: Man, Controller of the Universe. The male figure in the center of the mural is an idealization of modern man (the gendered form is significant) and his power to create himself and his environment. Here we have modern man as a product of his own will and skill, free from the shackles of tradition or physical constraints. As controller of the universe, he can shape space and time as he pleases, conquering them once and for all. Rivera's mural may seem now delirious and a gross exaggeration of what modernity is about, but in a less polished form it contains the same idea of human mastery over oneself and nature. After the modern project has succeeded in reaching almost every nook and cranny of the world, the outer limits of this drive for universal mastery have become apparent. At that point in history has the global age started to emerge, when the hubris of modernity has been exposed, and we have discovered that we are dependent on a series of global systems that we do not fully understand and much less control, at a time in which such knowledge is perceived to be key in order to secure our future survival.

The common folk from the Renaissance who looked at the paintings by the late medieval master Cimabue had no trouble identifying the different motifs and scenes depicted in the paintings and probably worshipped those images with as much fervor as their ancestors. However, they might have realized that the figures by Cimabue had a rather flat and hieratic feel compared to the images being painted by the artists of their own time. The introduction of perspective and realism were not merely innovations in the history of art but rather the result of deep cultural shifts. A similar mixed feeling of recognition and distance encounters us when we watch Diego Rivera's mural. The motifs of modernity are still among us and yet something profound has changed.

\section{References}

Albrow, Martin. 1996. The Global Age: State and Society Beyond Modernity. Cambridge: Polity Press.

Albrow, Martin. 2014. Global Age: Essays on Social and Cultural Change. Frankfurt am Main: Klostermann.

Ampuja, Marko. 2011. Globalization Theory, Media-Centrism and Neoliberalism: A critique of Recent Intellectual Trends. Critical Sociology 38 (2): 281-301.

Bauman, Zymunt. 2000. Liquid modernity. Cambridge: Polity Press.

Bauman, Zygmunt and Carlo Bordoni. 2014. State of Crisis. Cambridge: Polity Press.

Beck, Ulrich. 1992. Risk Society. Towards a New Modernity. London: Sage.

Bell, Daniel.1973. The Coming of Post-Industrial Society: A Venture in Social Forecasting. New York: Basic Books.

Bennet, Jane. 2010. Vibrant Matter: A Political Ecology of Things. Durham, NC: Duke University Press. 
Bergman, Michael K. 2001. The Deep Web: Surfacing Hidden Value. The Journal of Electronic Publishing 7 (1). Accessed 3 June 2015. http://quod.lib.umich.edu/cgi/t/text/textidx?c=jep; view=text;rgn=main;idno=3336451.0007.104

Burkart, Patrick. 2014. Pirate Politics: The New Information Policy Contests. Cambridge, Mass: MIT Press.

Deuze, Mark. 2012. Media Life. Cambridge: Polity Press.

Diamond, Jared. 2005. Collapse: How Societies Choose to Fail or Survive. London: Penguin.

Eisenstadt Shmuel. 2002. Multiple Modernities. New Brunswick, N.J.: Transaction Publishers.

Elliott, Aanthony. 2001. Concepts of the Self. Cambridge: Polity Press.

IPCC. 2014. Climate Change 2014: Impacts, Adaptation, and Vulnerability. Conducted by Working Group II to the Fifth Assessment Report of the Intergovernmental Panel on Climate Change). Cambridge: Cambridge University Press.

Fuchs, Christian. 2014. Social Media. A Critical Introduction. London: Sage.

Fukuyama, Francis. 1992. The End of History and the last Man. London: Hamish Hamilton.

Giddens, Anthony. 1990. The Consequences of Modernity. Cambridge: Polity in association with Blackwell.

Giddens, Anthony. 1991. Modernity and Self-Identity: Self and Society in the Late Modern age. Cambridge: Polity Press.

Habermas, Jürgen. 1987. The Philosophical Discourse of Modernity: Twelve Lectures (F.G. Lawrence, Trans. Cambridge, MA: MIT Press (Original work published 1985).

Habermas, Jürgen. 2009. Europe: the faltering project. Cambridge: Polity Press.

Klein, Naomi. 2014. This Changes Everything: Capitalism vs. the Climate. London: Allen Lane.

Joseph, George Cheverghese, Vasu Reddy and Mary Searle-Chatterjee. 1990. Eurocentrism in the Social Sciences. Race and Class 31(4): 1-26.

Latour, Bruno. 1993. We Have Never Been Modern (C. Porter, Trans.). Cambridge, Mass: Harvard University Press (Original work published 1991).

Levy, Pierre. 1997. Collective Intelligence: Mankind's Emerging World in Cyberspace. New York: Plenum Trade.

Marx, Karl. 1977. Capital. Volume 1. A Critique of Political Economy (B. Fowkes, Trans.). New York: Vintage Books (Original work published 1867).

Mason, Roger. 1998. The Economics of Conspicuous Consumption: Theory and Thought since 1700. Cheltenham: Edward Elgar.

Massey, Doreen. 1994. Space Place and Gender. Cambridge. Polity Press.

Meehl, Gerald A, Washington, Warren M, Santer, Benjamin D, Collins, Williams D, Arblaster, Julie M, Hu, Aixue, Lawrence, David M, Teng, Haiyan, Buja, Lawrence E and Strand Warren G. 2006. Climate Change Projections for the Twenty-First Century and Climate Change Commitment in the CCSM3. Journal of Climate 19: 2597-2616.

Perelman, Michael. 2000. The Invention of Capitalism: Classical Political Economy and the Secret History of Primitive Accumulation. Durham, NC: Duke University Press.

Pemberton, Jo-Anne. 2001. Global Metaphors: Modernity and the Quest for One World. London: Pluto Press.

Rosenberg, Justin. 2000. The Follies of Globalisaton Theory. London: Verso

Rosenberg, Justin. 2005. Globalization Theory: A Post Mortem. International Politics 2005 (42): $2-74$.

Scott, David. 2004. Conscripts of Modernity: The Tragedy of Colonial Enlightenment. Durham: Duke University Press.

Speier, Cheri, Valacich, Joseph and Iris Vessey.1999. The Influence of Task Interruption on Individual Decision Making: An Information Overload Perspective. Decision Sciences 30 (2): 337-360.

Steffen, Will, Åsa Persson, Lisa Deutsch, et al. 2011. The Anthropocene: From Global Change to Planetary Stewardship. AMBIO 40: 739. 
Svensson, Jakob. 2008. Expressive Rationality: A Different Approach for Understanding Participation in Municipal Deliberative Practices. Communication, Culture and Critique 1 (2): 203-221.

Svensson, Jakob. 2011. Theorizing Citizenships in Late Modern ICT Societies. TripleC 9 (2): 277-288.

Taylor, Charles. 2007. A Secular Age. Cambridge, Mass.: Harvard University Press.

Taylor, Mark. C. 2003. The Moment of Complexity. Emerging Network Culture. Chicago: The University of Chicago Press.

Thussu, Daya Kishan. 2006. International Communication: Continuity and Change. 2nd edition. London: Hodder Arnold.

Tomlinson, John. 1999. Globalization and Culture. Cambridge: Polity Press.

Turner, Bryan S. 2008. The Constructed Body. In Handbook of Constructionist Research, edited by James A Holstein and Jaber F Gubrium, 493-510. New York: Guilford Press.

Urry, John. 2001. Global Complexity. Cambridge: Polity Press.

Van Dalen, Arjen. 2012. The Algorithms Behind the Headlines. How Machine-Written News Redefines the Core Skills of Human Journalists. Journalism Practice 6 (5-6): 648-658.

Van Dijck, José. 2013. The Culture of Connectivity: A Critical History of Social Media. Oxford: Oxford University Press.

Van Dijk, Jan. 2012. The Network Society. 3rd Edition. Thousand Oaks: Sage.

Vásquez, Manuel. 2012. Grappling with the Legacy of Modernity: Implications for the Sociology of Religion. In Religion on the Edge: De-centering and Re-centering the Sociology of Religion, edited by Courtney Bender, Wendy Cadge, Peggy Levitt and David Smilde, 2342. Oxford: Oxford University Press.

Wallerstein, Immanuel. 1995. Historical Capitalism with Capitalist Civilization. London: Verso. Wang, Wendy, Kim Parker and Paul Taylor. 2013. Breadwinner Moms: Mothers are the Sole or Primary Provider in Four-in-Ten Households with Children-Public Conflicted about the Growing Trend. Report for Pew Research Center. Accessed 21 May 2015, http://www.pewsocialtrends.org/2013/05/29/breadwinner-moms/.

Weber, Max. 1992. The Protestant Ethic and the Spirit of Capitalism (T. Parsons, Trans.). London: Routledge (Original work published 1905).

\section{About the Authors}

Oriol Poveda Guillén

Holds a MA in Jewish Philosophy and is currently a PhD student in sociology of religion at Uppsala University, Sweden. His current research interests revolve around posthumanism and its possibilities for material (re)enchantment. Besides his scholarly endeavors, he has been working in the past for grassroots media organizations in Mexico and Israel/Palestine.

\section{Jakob Svensson}

Dr. Jakob Svensson is holding a position of associate professor in Media and Communication Studies at Uppsala University, Sweden. Dr Svensson directs the MA program in Digital Media and Society. His research focuses on two main areas: political participation on digital media platforms and mobile communication in so-called developing regions. 